Kushmar L.V., associate professor Kyiv National University of Trade and Economics

Kyiv, Ukraine

ORCID iD: 0000-0003-0407-6267

\title{
ERASMUS+ IN UKRAINE
}

Strategic Partnerships of Ukraine and European Union (EU) provide opportunities for a wide variety of public, private, and non-governmental organisations to implement a broad range of activities including, for example:

- strengthening cooperation and networking between organisations; promoting the development, testing, and implementation of innovative practices;

- promoting the recognition and validation of knowledge, skills, and competences;

- promoting cooperation between regional authorities to develop new systems for education, training, and youth;

- supporting learners with disabilities and special needs and ease their transition to the labour market;

- supporting education and training professionals to promote equity, diversity, and inclusion in learning;

- romoting integration of newly arrived migrants and raising awareness about the refugee crisis in Europe;

- romoting entrepreneurship and active citizenship among young people.

Strategic Partnerships can be of different sizes and conduct different activities depending on the objective of the project, the organisations involved, the expected impact, and other elements.

Erasmus + is the European Union programme for education, training, youth and sport for the period 2014-2020. Erasmus + funds academic mobility and cooperation projects that involve partners from «Programme Countries» and «Partner Countries» throughout the world. The 33 programme countries comprise the $28 \mathrm{EU}$ Member States plus five other European countries. Erasmus + supports activities that are closely matched with the EU's priorities for cooperation policy with partner countries and regions. Three years into the programme, we can see how popular these initiatives are with countries from the region. 
The actions of the Erasmus + programme are divided into decentralised actions and centralised actions. The decentralised actions are managed in each programme country by National Agencies that are appointed by their national authorities. The centralised actions are managed at a European level by the Education, Audiovisual and Culture Executive Agency located in Brussels.

The aim of Erasmus+ is to contribute to the Europe 2020 strategy for growth, jobs, social equity and inclusion, as well as the aims of ET2020, the EU's strategic framework for education and training. Erasmus + also aims to promote the sustainable development of its partners in the field of higher education, and contribute to achieving the objectives of the EU Youth Strategy.

For over 30 years, students and staff have moved between European universities in the Erasmus programme. Since 2015, Erasmus + has also allowed short-term mobility to Europe from other parts of the world for students, researchers, and staff. This two-way mobility allows students to study in a foreign university for 3-12 months and obtain credits, which are then recognised at the sending institution as part of their degree. A grant for staff mobility is also possible for 5-60 days.

There are distinct budgets for different regions of the world that are divided between all the European countries. Programme-Country institutions make up bilateral partnerships with universities from Eastern Partnership countries and apply on behalf of their partners.

In the framework EU Erasmus + Programme: Learning Mobility Intenational Credit Mobility Action, students may receive grants for studying or being trained abroad totaling up to 12 months maximum per each cycle of study: during the first study cycle (Bachelor) including the short-cycle (EQF levels 5 and 6); during the second study cycle (Master EQF level 7); during the third cycle as doctoral candidate (Doctoral level or EQF level 8).

The duration of a traineeship by recent graduates counts towards the 12 months maximum of the cycle during which they apply for the traineeship. Total number of scholarships won by Ukrainian Higher Education Institutions for 2015-2018: 4550.

The strategic partnership between the EU and Ukraine, based on shared values and interests, is a vital factor of stability and prosperity in Europe.

\section{Referenses}

1. Erasmus+UA [Electronic Resource]. - Resource Access Mode : http://erasmusplus.org.ua 